\title{
The DISCO App: Evaluating an Electronic Patient Intervention to Reduce The Financial Burden of Cancer Through Improved Cost Communication In A Non-Randomized Pilot Trial
}

\author{
Lauren M. Hamel ( $\nabla$ hamell@karmanos.org ) \\ Wayne State University School of Medicine https://orcid.org/0000-0002-8910-7079 \\ David W. Dougherty \\ Dana-Farber Cancer Institute
}

Theresa A. Hastert

Wayne State University School of Medicine

Erlene K. Seymour

Wayne State University School of Medicine

Seongho Kim

Wayne State University School of Medicine

Hadeel Assad

Wayne State University School of Medicine

Jasminder Phalore

Wayne State University School of Medicine

Roger Soulliere

Wayne State University School of Medicine

Susan Eggly

Wayne State University School of Medicine

\section{Research}

Keywords: financial toxicity, patient active participation, question prompt list, cancer treatment cost discussion, app-based intervention

Posted Date: January 20th, 2021

DOl: https://doi.org/10.21203/rs.3.rs-149395/v1

License: (9) This work is licensed under a Creative Commons Attribution 4.0 International License. Read Full License 


\section{Abstract}

Background: Financial toxicity affects $30-50 \%$ of people with cancer in the US. Although experts recommend patients and oncologists discuss treatment cost, cost discussions occur infrequently. Using a non-randomized pre-test post-test design, we pilot-tested the feasibility, acceptability and preliminary effectiveness of the DIScussions of COst (DISCO) App, a patient communication intervention designed to improve the frequency of cost discussions and related outcomes.

Methods: While waiting to see their oncologist, patients ( $n=32)$ used the DISCO App on a tablet. Clinic visits were video recorded and patients completed pre- and post-intervention measures of self-efficacy for managing treatment costs, self-efficacy for interacting with oncologists, cost-related distress, and perceptions of the DISCO App. Coders observed the recordings to determine the presence of cost discussions, initiators, and topics.

Results: Most patients (84\%) reported needing $\leq 15$ minutes to use the DISCO App. Patients reported the DISCO App made it easier to ask cost-related questions. Findings showed increased self-efficacy for managing treatment costs $(p=.02)$ and for interacting with oncologists $(p=.001)$. All clinic visits included a cost discussion.

Conclusion: The DISCO App is feasible, acceptable, and effective in prompting cost discussions and improving outcomes. Prompting patients to discuss costs before meeting with an oncologist may improve treatment cost discussions and related outcomes.

Trial registration: Clinical Trials.gov registration number: NCT03676920 (September 19, 2018)

\section{Background}

Financial toxicity, the severe material and psychological burden of the cost of cancer treatment, affects an estimated $30-50 \%$ of patients with cancer in the United States, including people with health insurance [1]. As the cost of care increasingly shifts to patients, more patients must deplete their savings, incur debt and file for bankruptcy [2-7]. On average, cancer patients are responsible for $\$ 16,000$ annually for direct and indirect out-of-pocket treatment costs [8]. Patients may also suffer great psychological harm, including significant, even catastrophic, levels of cost-related distress [9-13].

Cancer treatment cost and financial toxicity can influence treatment decisions, treatment adherence, and health outcomes, including an increased risk of mortality [1,14-20]. Treatment costs factor into patients' decisions about treatment, [21-24] including whether to participate in clinical trials [22, 25]. For example, patients with lower incomes are more likely to choose treatments with lower costs even if those treatments have lower survival and higher toxicity [23]. To offset cost, patients may deviate from recommended treatment (including treatment for side effects) $[15,26,27]$ and/or forgo treatment altogether [24]. A study of 254 patients being treated with either chemotherapy or hormonal therapy found that $20 \%$ took less than, partially filled, or avoided filling the prescribed medication due to the out- 
of-pocket costs [15]. Another study of 164 patients with solid tumors found that $45 \%$ were non-adherent to treatment due to cost [28]. A study of 1556 cancer survivors found that those who reported financial problems were more likely to delay ( $18.3 \%$ vs. $7.4 \%$ ) or forgo treatment ( $13.8 \%$ vs. $5.0 \%)$ compared to respondents without financial problems [29].

Addressing financial toxicity requires policy changes at the national, state, and hospital levels. In the meantime, however, increasing the frequency and quality of patient-oncologist treatment cost discussions early in diagnosis and treatment may help alleviate financial toxicity $[10,14,30-33]$ by improving patients' knowledge, self-efficacy, and ability to manage potential costs, and by connecting patients with vital economic support [34]. Most patients (80\%) and oncologists (80\%) want to discuss treatment costs, $[35,36]$ and professional organizations such as the American Society of Clinical Oncology (ASCO) encourage oncologists to discuss treatment cost with patients [14]. However, research has found that these discussions are infrequent $[36,37]$. In our previous observational study of videorecorded treatment discussions between patients with cancer and their oncologists $(n=103)$, we found that cost discussions occurred in only $45 \%$ of treatment discussions [38]. When cost was discussed, it was mostly patient-initiated (63\%) and focused more on indirect costs (e.g., time off work) than on direct costs (e.g., copayments; [39]. Without a cost discussion early in treatment decision making, patients are unlikely to be referred for guidance or assistance in a timely manner, thereby missing out on early financial and psychological support, which are critical steps in reducing longer-term financial toxicity [15, $34,40]$ and improving treatment adherence $[10,28,41]$. Research shows that, in the short term, patientoncologist treatment cost discussions can increase referrals for support (e.g., social work; [34] and reduce cost-related distress [10]. Longer-term effects include improved financial toxicity [10] and treatment adherence [41].

Another benefit of holding cost discussions early in treatment planning is that they can improve patient self-efficacy, or the expectation that one can successfully perform a behavior [42], for managing cost [43, 44]. Similarly, researchers have demonstrated the positive influence of improving another aspect of selfefficacy-activating patients to manage their own health, and more specifically, actively participating in clinical interactions by asking questions, stating concerns, and making assertions [45-48]. Research on clinical communication in many medical settings shows patient active participation plays an important role in short-, intermediate-, and long-term outcomes $[49,50]$. Patient active participation influences the amount of information physicians provide [46, 51, 52], the information exchange process (Barton et al., 2020), the treatment physicians recommend [48], topics patients and physicians discuss [53, 54], patient healthcare decisions [55], and patient psychosocial and physical health outcomes [56, 57]. Increasing patient active participation during clinical interactions has been shown to change the content and quality of patient-physician interactions and outcomes, and thus has the potential to improve the frequency and quality of patient-oncologist treatment cost discussions. It is also possible that self-efficacy may be the primary mechanism through which patient-oncologist treatment cost discussions mitigate the burden of financial toxicity. 
Question prompt lists (QPLs) are simple communication tools that have been shown to improve patient active participation in cancer treatment discussions and prompt discussion about specific topics during clinical interactions. QPLs are comprised of a list of questions provided to patients to encourage them to prepare for visits by considering questions they would like to ask their healthcare provider [58-60]. QPLs have been shown to improve communication quality (e.g., patient active participation in interactions, [47]; patient-oncologist information exchange, [61]; topics discussed [53, 54]; patient psychological and cognitive outcomes (e.g., satisfaction, anxiety; information recall; [58] and patient role in treatment decisions and trust in their oncologist $[58,60,62]$.

In the current research, we build upon current QPLs in two ways. First, while most current QPLs have few if any questions regarding treatment costs, we developed a QPL that specifically addresses this topic. Second, while most current QPLs are paper-based and static, we developed a way to tailor the QPL content to patients' specific needs and clinical setting through the use of an electronic QPL in the form of an application or "app" provided to patients in the clinic prior to a patient's scheduled visit with an oncologist to discuss treatment.

Building on our experience with testing QPLs in oncology outpatient clinics [47, 63-65] we designed and built a novel communication tool, the DIScussion of COst Application (DISCO App; Fig. 1; [66]. We designed the DISCO App to be app-based because using an electronic format allows the tool to be tailorable to the individual [58] enhances eventual scalability to other populations, and has the potential to be integrated into EMRs and patient portals. In response to concerns that physicians may be unwilling or unable to respond appropriately to patient questions about treatment cost $[67,68]$, we also developed a treatment cost discussion "tip sheet" for oncologists. The tip sheet emphasizes oncologists' role in cost discussions (as recommended by ASCO) and provides ways to overcome identified barriers to cost discussions $[36,37,67,68]$.

\section{DISCO App intervention}

The DISCO App (Fig. 1; [66] is displayed on an iPad provided to patients just prior to their second interaction with their oncologist, in which they discuss and finalize treatment plans. The DISCO App opens and the QPL is introduced with text that explains that the DISCO App includes a short survey, which will lead to some cost-related questions the patient can consider asking the oncologist. This section asks patients to enter their demographic information and their financial circumstances. Specifically, patients respond to 17 questions, such as "How much do you know about your insurance coverage?"; "Are you currently employed?"; "Is there anyone who helps you when you're sick or need help of any kind?". Based on patient responses, an individually-tailored QPL with up to 18 cost-related questions in 7 categories is generated (Table 1). For example, patients who indicate they are employed will be prompted to ask: "Can I schedule my treatment around my job?"; patients who indicate transportation concerns will be prompted to ask: "Are services available if I can't find someone to drive me?" Patients who indicate they are unfamiliar with their insurance coverage will be prompted to ask: "Is there someone I can talk to about my insurance and treatment cost questions?" All patients, regardless of their responses, are provided with 
four general questions about their diagnosis and have the option of adding in any of their own questions. Once they have completed the questions and received their individualized QPL, they can take the iPad or a printed question list into the meeting with the oncologist. 
The DISCO App's Prompted Questions by Question Type

\section{Cost of appointments and treatments}

1. How much will I have to pay for my treatment?

2. Is there a less expensive drug, like a generic, that will be equally effective?

3. How many visits will I have? I may have to pay each time I come to the cancer center (co-pay, parking, etc.).

4. What happens if I can't pay for some of my treatment costs?

Help with understanding my treatment costs and what my insurance covers

5. Do I need additional or supplemental insurance coverage?

6. Do I have a co-pay every time I come to the cancer center?

7. Is there someone I can talk to about my questions about my insurance and treatment costs?

Transportation to and parking at the cancer center

8. Does someone need to drive me to treatment appointments?

9. Are services available if I can't find someone to drive me?

10. How much does parking cost?

Living far from the cancer center

11. Is it possible for me to receive my treatment closer to where I live?

12. Are there free or reduced-cost hotels nearby for me and my family?

Working during treatment

13. Can I keep working during treatment? If not, when can I go back to work?

14. Can I schedule my treatment around my job?

15. Do I need to file Family and Medical Leave Act (FMLA) paperwork? If so, how?

Assistance programs

16. Are assistance programs available to help me with treatment costs or other expenses or needs?

17. If I need a wig or other supplies, is there somewhere I can get them free or at a reduced cost?

Family and living responsibilities

18. Can I schedule my treatment around my family's schedule?

General questions about cancer and treatment (all patients will get these)

19. What is my diagnosis and stage? 


\section{Cost of appointments and treatments}

20. Is it possible to cure my cancer?

21. What is my treatment plan?

22. Are there clinical trials I can participate in? I fso, will this cost more or less than standard treatment?

\section{Methods}

Ethical approval for this study was granted by the Wayne State University (WSU)/Karmanos Cancer Institute (KCl) institutional review board (IRB \# 115117B3E(M)). The extension of CONSORT 2010 checklist specifically for pilot trials was used for reporting the study.[69]

\section{Research aims}

A large-scale and longitudinal randomized controlled trial is needed to determine if the DISCO App will lead to the anticipated short- and longer-term patient outcomes, as compared to usual care. However, because this is a newly-developed technology-based intervention, we must first conduct preliminary testing. The purpose of this study was to pilot-test the DISCO App in an oncology clinic setting to determine its feasibility, acceptability, and preliminary effectiveness on short-term outcomes including: patient-oncologist treatment cost discussions during treatment discussions, patients' self-efficacy for managing treatment costs, patients' self-efficacy for interacting with physicians, and patients' treatment cost-related distress.

\section{Design}

For this pilot trial, we employed a non-randomized pre-test post-test design to test the feasibility, acceptability and preliminary effectiveness of the DISCO App. This was a one-arm trial in which all recruited patients were assigned to the intervention arm.

\section{Participants and Setting}

Data were collected in two outpatient community clinics affiliated with WSU/KCl located in Southeast, Michigan from August 2018 to December 2019.

Patients were eligible to participate if they were recently diagnosed with breast, lung, prostate, or colorectal cancer and were scheduled to see a participating radiation oncologist for an initial treatment discussion. Oncologists were eligible if they routinely treated patients for breast, lung, prostate, or colorectal cancer. Patients were identified by a clinic member of the research team who reviewed participating oncologists' schedules and contacted eligible patients prior to their appointment to determine interest in participating. Interested patients were consented on the day of their appointment and prior to meeting with their oncologist. 


\section{Procedure and Measures}

Upon recruitment into the study, oncologists completed a one-time baseline questionnaire where they provided information on their sex and race/ethnicity, and then received the oncologist treatment cost discussion tip sheet. After patients were recruited, they completed a baseline questionnaire that assessed sociodemographic characteristics and other personal attributes.

Patients arrived up to one hour before their scheduled appointment to complete self-report measures on an iPad through an electronic survey service (Qualtrics). After completing pre-interaction measures, a member of the research staff showed patients the DISCO App on an iPad and provided a brief explanation on how to use it. The iPad was connected to a printer on-site, allowing patients to print their individually-tailored QPL created from the DISCO App for note-taking.

Each examination room was equipped with unobtrusive digital audio and video devices that recorded the examination room during the clinical interaction. This recording system has been used by the study team for more than 15 years, $[28,41]$ and research has strongly suggested that video recording has little impact on participants' verbal or nonverbal behaviors [58] and provides enhanced validity compared with audio recording alone [59].

After the patient-oncologist treatment discussion, patients completed post-discussion self-report measures. All patients and oncologists provided consent as participants, which included specific permission to be video recorded.

\section{Feasibility}

To assess the feasibility of the DISCO App, patients reported how long it took them to use the DISCO App and research staff collected a copy of the printed question list to determine how many questions patients selected from the DISCO App to be printed for a discussion with their oncologist. We also tracked if any patient needed assistance with using the DISCO App and if any participant refused to be video recorded and/or left the study early.

\section{Acceptability}

To assess the acceptability of the DISCO App, after the clinical interactions, patients completed measures of their perceptions of the DISCO App ("the questions in the DISCO App were easy to understand"; "the DISCO App made it easier to ask my doctor cost-related questions"; "some of the questions in the DISCO App were useful to me as I was talking with my doctor"; "some of the questions in the DISCO App made me uncomfortable") on a Likert-type scale ( 1 = strongly disagree to 5 = strongly agree).

\section{Preliminary Effectiveness Self-report Measures}

To assess the preliminary effectiveness of the DISCO App, patients completed pre- and post-interaction measures of financial toxicity- and cost discussion-related outcomes including self-efficacy for managing treatment costs (e.g., how confident are you in your ability to find out how to pay for direct costs that 
arise with treatment?; 5 = very confident, $1=$ not at all confident[70], self-efficacy for interacting with physicians (e.g., how confident are you in your ability to know what questions to ask a doctor?; 5 = very confident, 1 = not at all confident; [71], and cost-related distress (e.g., I am concerned about my ability to afford to pay for my cancer treatment; 5 = strongly agree, $1=$ strongly disagree).

\section{Oncologist and Patient Interaction Coding}

To further assess the preliminary effectiveness of the DISCO App, we analyzed video-recorded patientoncologist treatment cost discussions using methods from our previous research [38]. Patient-oncologist cost discussions were broadly defined as verbal discussion of topics related to a monetary expense for the patient for cancer treatment. This includes direct costs such as appointment copayments and indirect costs such as loss of income due to time off from work.

Two trained coders observed all video-recorded interactions to identify the presence of cost discussions using a validated coding system and, when these occurred, the initiator (patient or oncologist) and the cost topics raised, from a list identified from previous research, including insurance/copayment, out-ofpocket costs, time off from work, transportation/parking, lodging, social work/financial navigation, and scheduling treatment around patient's schedule [38].

Interrater reliability was assessed using $20 \%$ of the sample of video-recorded interactions. First, the coders identified the presence of cost discussions and reliability was determined using percent agreement, which was $87.5 \%$. Second, the coders labeled each cost discussion's initiator and topic. Reliability for this phase was determined by Cohen's kappa $(K=1.0)$. Because the high $K$ value suggested high intercoder reliability, the remaining video-recorded interactions were coded by one coder each.

\section{Data Analysis}

Data included patient and oncologist self-report sociodemographics, patient perceptions of the DISCO App, patient self-reported outcome variables, and coder ratings of the video-recorded clinical interactions. We used descriptive statistics to describe the patient and oncologist participant sociodemographic characteristics, feasibility, acceptability and preliminary effectiveness. To describe feasibility, we determined how long patients reported using the DISCO App and how many questions patients selected from list the DISCO App created for them. We also determined how many patient and oncologist participants agreed to have their visits video recorded and if any patients dropped out of the study. To assess acceptability, we determined patients' perceptions of the DISCO App. To assess preliminary effectiveness, we determined presence, initiator, and topics of any cost discussions that occurred during the video-recorded interactions. We used two-tailed paired samples $t$ tests to determine any pre- to postintervention changes in patient self-report outcomes of self-efficacy for managing treatment costs, selfefficacy for interacting with oncologists, and cost-related distress. For all analyses a was set at $p<.05$ (two-tailed).

\section{Results}


Thirty-two recently-diagnosed patients of three participating oncologists agreed to participate. Most $(\mathrm{n}=$ $30,94 \%$ ) interactions were video recorded (in two cases technical difficulties prevented recording). The sociodemographic characteristics of patients and oncologists are reported in Table 2. Most patients had breast cancer (84\%). 
Table 2

Patient and Oncologist Sociodemographics

\begin{tabular}{|c|c|}
\hline Patients ${ }^{1}$ & $\begin{array}{l}\text { Total } \\
\mathrm{n}=\mathbf{3 2}\end{array}$ \\
\hline \multirow[t]{2}{*}{ Age } & $M=61.48$ \\
\hline & $(\mathrm{SD}=8.08)$ \\
\hline Female & $31(97 \%)$ \\
\hline \multicolumn{2}{|l|}{ Race/Ethnicity } \\
\hline Caucasian or White/Non Hispanic & $32(100 \%)$ \\
\hline \multicolumn{2}{|l|}{ Education } \\
\hline$<$ High School & $1(3 \%)$ \\
\hline Graduated High School & $9(28 \%)$ \\
\hline Some College & $9(28 \%)$ \\
\hline Graduated College & $11(34 \%)$ \\
\hline Post-graduate degree & $1(3 \%)$ \\
\hline \multicolumn{2}{|l|}{ Marital Status } \\
\hline Married/Partnered & $20(63 \%)$ \\
\hline Divorced/Widowed/Separated & $9(28 \%)$ \\
\hline Single & $1(3 \%)$ \\
\hline \multicolumn{2}{|l|}{ Annual Household Income } \\
\hline $0-\$ 19,999$ & $4(13 \%)$ \\
\hline$\$ 20,000-\$ 39,999$ & $6(19 \%)$ \\
\hline$\$ 40,000-\$ 59,999$ & $14(44 \%)$ \\
\hline$\$ 60,000-\$ 79,999$ & $8(25 \%)$ \\
\hline \multicolumn{2}{|l|}{ Employment } \\
\hline Employed & $12(38 \%)$ \\
\hline Unemployed but looking for employment & $1(3 \%)$ \\
\hline Retired & $14(44 \%)$ \\
\hline Disabled/unemployed for another reason & $5(16 \%)$ \\
\hline
\end{tabular}




\begin{tabular}{|c|c|}
\hline Patients ${ }^{1}$ & $\begin{array}{l}\text { Total } \\
\mathrm{n}=32\end{array}$ \\
\hline Medicaid & $8(25 \%)$ \\
\hline Medicare/Supplement & $9(28 \%)$ \\
\hline Private insurance from employer & $13(41 \%)$ \\
\hline Private insurance the patient pays for & $2(6 \%)$ \\
\hline \multicolumn{2}{|l|}{ Primary Tumor Site } \\
\hline Breast & $27(84 \%)$ \\
\hline Lung & $5(16 \%)$ \\
\hline Interaction Length & $M=25.7$ \\
\hline (in Minutes) & $S D=5.1$ \\
\hline \multicolumn{2}{|l|}{ Oncologists $(n=3)$} \\
\hline Male & $3(100 \%)$ \\
\hline \multicolumn{2}{|l|}{ Race/Ethnicity } \\
\hline Caucasian or White & $2(50 \%)$ \\
\hline Asian or Pacific Islander & $1(50 \%)$ \\
\hline \multicolumn{2}{|l|}{$\begin{array}{l}\text { Number of participating } \\
\text { patients seen }\end{array}$} \\
\hline MD 1 & $25(78 \%)$ \\
\hline MD 2 & $7(22 \%)$ \\
\hline \multicolumn{2}{|c|}{${ }^{1}$ Some data are missing because of omissions in patients' } \\
\hline \multicolumn{2}{|c|}{ Responses (Education and Marital Status are not available for one and two patients, respectively). } \\
\hline
\end{tabular}

\section{Feasibility}

All patient and oncologist participants agreed to have their interactions video recorded and all patients completed all procedures for the study. Most patients (84\%) reported needing 15 minutes or less to use the DISCO App, while $13 \%$ needed 16 to 30 minutes, and $3 \%$ needed 31 to 45 minutes. All patients finished using the DISCO App without assistance during the time they were in the exam room and waiting to see their oncologist. On average, patients selected 6.5 questions from the individualized question 
prompt list to print, with a range of 1-18 selected questions. We emphasize that the list of questions was individually-tailored so not every patient was presented with all 18 possible questions.

\section{Acceptability}

Patients reported that the questions in the DISCO App were easy to understand ( $M=4.5 ; S D=.8)$; the DISCO App made it easier to ask their doctor cost-related questions $(M=3.8 ; S D=.8)$; and that some of the questions in the DISCO App were useful to them as they were talking with the doctor $(M=3.8 ; S D=.7)$. They also reported that the questions in the DISCO App did not make them feel uncomfortable $(M=4.1$; $\mathrm{SD}=1.1)$.

\section{Preliminary Effectiveness}

\section{Observed Cost Discussions}

Cost discussions occurred in all 30 of the video-recorded interactions. The number of cost discussions per interaction ranged from 1-6, for a total of 97 individual cost discussions across all interactions. Patients and oncologists were equally likely to initiate the first cost discussion during a clinical interaction, and the topic most-frequently discussed first was insurance. Oncologists were more likely to initiate any subsequent cost discussions. The most frequent patient-initiated topics were insurance followed by time off from work. The most frequent oncologist-initiated topics were social work/financial navigation followed by insurance (Table 3).

Table 3. Observed Treatment Cost Discussion by Initiator and Topic 


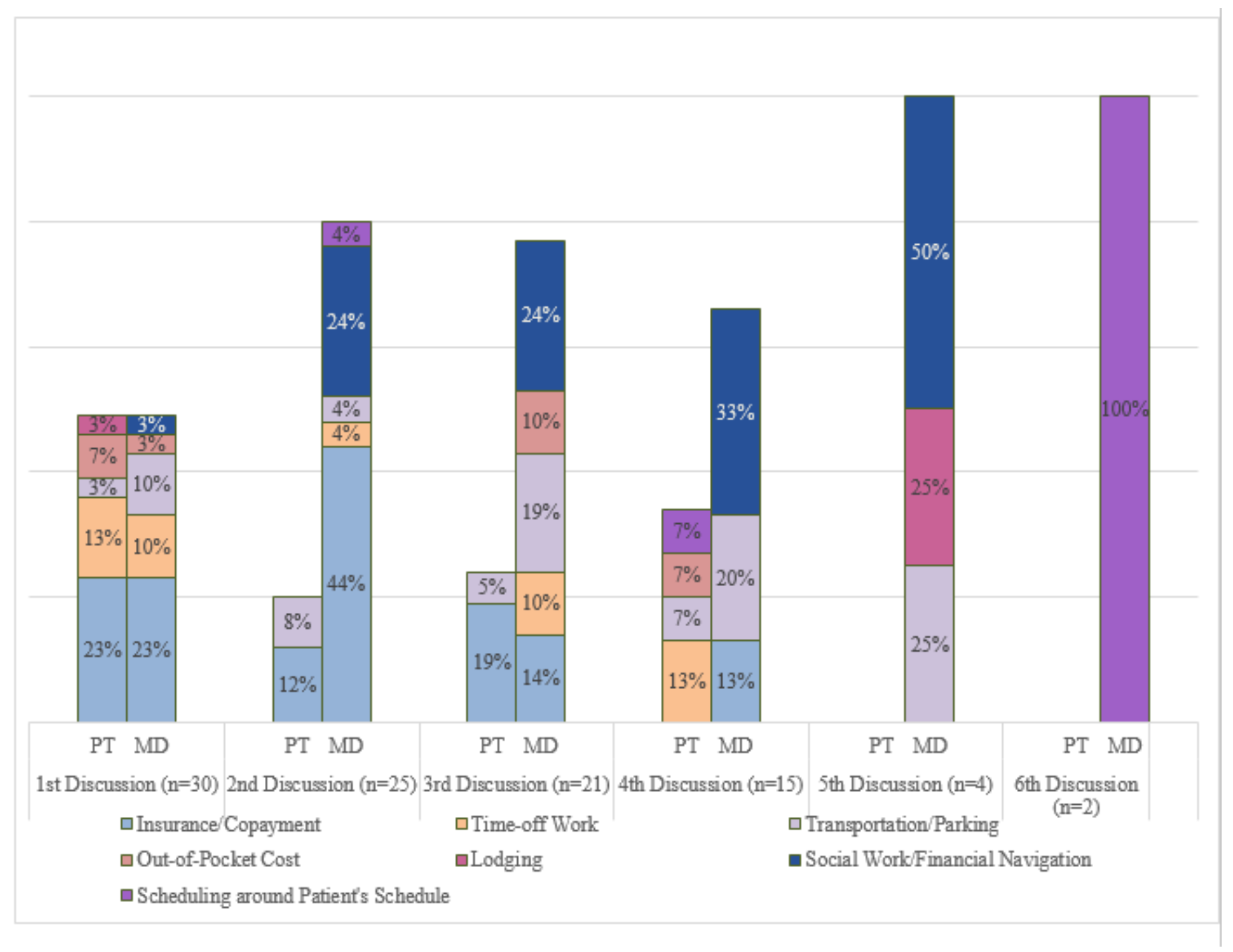

\section{Financial Toxicity-Related Outcomes}

We also examined whether the DISCO App influenced other financial toxicity- and cost discussion-related outcomes reported by patients before and after they used the DISCO App and subsequently met with their oncologist. There were significant pre- $(M=3.72, S D=1.22)$ to post- $(M=4.36, S D=.67)$ intervention increases in patients' self-efficacy for managing treatment costs $(t(31)=3.55, p=.001)$ and in patients' self-efficacy for interacting with physicians $(M=40.78, S D=6.69 ; M=43.84, S D=5.77 ; t(31)=3.86, p$ $=.001)$. There was also a non-significant decrease in pre- $(M=3.23, S D=.63)$ to post- $(M=3.09, S D=.77)$ DISCO App use in treatment cost-related distress $(t(31)=1.28, p=.21)$.

\section{Discussion}

To our knowledge, this study is among the first to investigate whether a patient-focused intervention can successfully prompt patient-oncologist treatment discussions, and, in turn, improve financial toxicityrelated outcomes for patients. Findings from this pilot test demonstrated that the DISCO App is both feasible to implement in a clinical oncology setting and acceptable to patients. Moreover, it appears to be effective in improving short-term outcomes, including prompting treatment cost discussions and 
increasing patient self-efficacy for interacting with physicians and managing costs. These promising findings suggest that through prompting cost discussions and improving short-term outcomes, the DISCO App may lead to improved longer-term outcomes, including the burden of financial toxicity and its consequences.

Treatment cost discussions have been identified as one way to help mitigate the deleterious experience of financial toxicity due to cancer treatment by increasing patients' self-efficacy in managing their treatment costs $[10,14,30-34]$. In a previous observational study we conducted also using video-recorded treatment discussions, we observed that only $45 \%$ of interactions had a treatment cost discussion [38]. Here, we observed that $100 \%$ of video-recorded treatment visits had at least one treatment cost discussion, and $70 \%$ of treatment discussions included at least three different treatment cost topics. We also observed improvements in other important patient outcomes, including self-efficacy for managing treatment costs and self-efficacy for interacting with physicians. We anticipate that patient self-efficacy may be the mechanism through which the DISCO App will improve outcomes. Specifically, we think patient self-efficacy will influence both the DISCO App's direct short-term intent - to prompt patientoncologist treatment cost discussions - and its indirect longer-term intent, to mitigate the experience of financial toxicity and improve treatment adherence. Of course, our pilot study design does not allow us to conclude with certainty that the DISCO App or cost discussions it prompted led to observed improvements in patient self-efficacy for managing their treatment cost or interacting with their physicians. However, these promising findings warrant further investigation into the more nuanced relationships between the short- and longer-term effects of the DISCO App and treatment cost discussions for patients.

\section{Practice Implications}

ASCO's Value of Cancer Treatment Options Framework [14] and its Patient-Clinician Communication Guideline [72] both encourage oncologists to discuss treatment costs with their patients. Despite these guidelines, however, research has shown that cost discussions infrequently occur and that physician engagement around cost concerns is an unmet patient need [73]. Many of the cost discussions we observed in the video-recorded data addressed cost-related topics beyond ASCO's more narrow definition of treatment costs. ASCO's tools focus exclusively on direct out-of-pocket costs for patients such as copayments or insurance costs [72]. In this study, both patients and oncologists initiated discussions about indirect costs for patients (e.g., taking time off from work, transportation to treatment appointments), which can often be just as detrimental to patients [74-77]. This may be evidence that oncologists are well positioned to address the indirect cost of care, even if the precise direct cost of treatments remain elusive, and that ASCO may need to expand its definition of treatment costs.

With regard to the concern that physicians may not be willing or able to respond to patients' cost-related questions, we observed that, once an initial cost discussion occurred in an interaction, oncologists were more likely to initiate subsequent cost discussions later in the interaction. Perhaps this demonstrates that oncologists are prepared to help patients with many of their cost-related concerns, and patients' prompts 
to discuss cost encourage oncologists to further the discussion. Surprisingly, we also observed that oncologists sometimes asked patients for their list of questions and responded to their questions, rather than waiting for patients to verbalize their questions. This was not part of our planned analyses, but future research should identify unintended effects of the cost-related question prompt list, whether positive or negative.

Since research has shown that, despite the guidelines from ASCO, treatment cost discussions do not occur regularly, perhaps these guidelines coupled with an individualized prompt from an intervention like the DISCO App just prior to meeting with an oncologist may help these discussions occur more frequently for patients. Lack of knowledge of the cost of treatment has been identified as a barrier to providers discussing treatment cost with patients [68]. Our findings, albeit preliminary, could be demonstrating that oncologists may have a better understanding of the costs of treatment than previously thought. Of course, additional work is needed to better understand how the presence of the question list produced by the DISCO App influences both the content and quality of cost discussions and patients' satisfaction with those discussions.

\section{Limitations}

Findings must be considered within the limitations of the study. This was a descriptive, one-arm pilot test using pre-post patient-reported measures and video-recordings to assess the DISCO App's feasibility, acceptability, and preliminary effectiveness on short-term outcomes. Also, most patient participants were women with breast cancer, which limits the generalizability of the findings $[77,78]$. Further study with a randomized controlled trial design is needed to assess these and longer-term outcomes, and this research is needed in a diverse patient population with regard to racial/ethnic background, gender, and cancer type.

\section{Conclusion}

In conclusion, we found the DISCO App to be feasible and acceptable in a clinic setting and effective at prompting treatment cost discussions between patients and oncologists and improving other patient outcomes related to financial toxicity. We note here that these findings provided preliminary evidence supporting a larger test of the DISCO App. The effectiveness of an enhanced version of the DISCO App on short- and longer-term patient outcomes, including patient-oncologist treatment cost discussions, is currently being tested in a randomized controlled trial with a diverse patient population (RSG-20-026-01CPHPS, Hamel, PI).

\section{Declarations}

\section{Ethics approval and consent to participate}

Ethical approval, including patient and physician consent to participate, for this study was granted by the Wayne State University (WSU)/Karmanos Cancer Institute (KCl) institutional review board (IRB \# 
115117B3E(M)).

\section{Consent for publication}

Not applicable

\section{Availability of data and materials}

The data that support the findings of this study are available from the corresponding author, [LMH], upon reasonable request.

\section{Competing interests}

The authors declare that they have no competing interests.

\section{Funding}

This work was supported by an internal grant from the Karmanos Cancer Institute, Detroit, MI (Hamel, PI). The funder played no role in the design of the study, data collection, analysis or interpretation, or writing the manuscript.

\section{Authors' contribution}

LMH: Conception, design, data acquisition, analysis, interpretation, manuscript writing and approval of submitted version.

DWD: Interpretation, manuscript writing and approval of submitted version.

TAH: Design, interpretation, manuscript writing and approval of submitted version.

EKS: Interpretation, manuscript writing and approval of submitted version.

SK: Data analysis, interpretation, manuscript writing and approval of submitted version.

HA: Interpretation, manuscript writing and approval of submitted version.

JP: Data acquisition, interpretation, manuscript writing and approval of submitted version.

RS: Interpretation, manuscript writing and approval of submitted version. 
SE: Conception, design, data acquisition, analysis, interpretation, manuscript writing and approval of submitted version

\section{References}

1. Altice CK, Banegas MP, Tucker-Seeley RD, Yabroff KR. Financial hardships experienced by cancer survivors: A systematic review. J Natl Cancer Inst. 2017;109:2.

2. Collins SR, Rasmussen PW, Doty MM, Beutel S. Americans' experiences with marketplace and medicaid coverage. Findings from the Commonwealth Fund affordable care act tracking survey, March-May 2015. Issue Brief (Commonw Fund). 2015;16:1-17.

3. PricewaterhouseCoopers. Medical cost trend: Behind the numbers 2016. https://www.pwc.com/us/en/health-industries/behind-the-numbers/assets/pwc-hri-medical-costtrend-chart-pack-2016.pdf; 2016.

4. American Society of Clinical Oncology. The State of Cancer Care in America, 2016: A report by the American Society of Clinical Oncology. J Oncol Pract. 2016;12:339.

5. Jagsi R, Pottow JA, Griffith KA, Bradley C, Hamilton AS, Graff J, et al. Long-term financial burden of breast cancer: experiences of a diverse cohort of survivors identified through population-based registries. J Clin Oncol. 2014;32(12):1269-76.

6. Ramsey S, Blough D, Kirchhoff A, Kreizenbeck K, Fedorenko C, Snell K, et al. Washington State cancer patients found to be at greater risk for bankruptcy than people without a cancer diagnosis. Health Aff (Millwood). 2013;32(6):1143-52.

7. The Kaiser Family Foundation: 2015 Employer Health Benefits Survey. http://kff.org/healthcosts/report/2015-employer-health-benefits-survey/; 2015.

8. Mariotto AB, Yabroff KR, Shao Y, Feuer EJ, Brown ML. Projections of the cost of cancer care in the United States: 2010-2020. J Natl Cancer Inst. 2011;103(2):117-28.

9. Fenn KM, Evans SB, McCorkle R, DiGiovanna MP, Pusztai L, Sanft T, et al. Impact of financial burden of cancer on survivors' quality of life. J Oncol Pract. 2014;10(5):332-8.

10. Bestvina CM, Zullig LL, Rushing C, Chino F, Samsa GP, Altomare I, et al. Patient-oncologist cost communication, financial distress, and medication adherence. J Oncol Pract. 2014;10(3):162-7.

11. Sharp L, Carsin AE, Timmons A. Associations between cancer-related financial stress and strain and psychological well-being among individuals living with cancer. Psychooncology. 2013;22(4):745-55.

12. Chino F, Peppercorn J, Taylor DH Jr, Lu Y, Samsa G, Abernethy AP, Zafar SY. Self-reported financial burden and satisfaction with care among patients with cancer. Oncologist. 2014;19(4):414-20.

13. Delgado-Guay M, Ferrer J, Rieber AG, Rhondali W, Tayjasanant S, Ochoa J, et al. Financial distress and its associations with physical and emotional symptoms and quality of life among advanced cancer patients. Oncologist. 2015;20(9):1092-8.

14. Schnipper LE, Davidson NE, Wollins DS, Blayney DW, Dicker AP, Ganz PA, Hoverman JR, et al. Updating the American Society of Clinical Oncology Value Framework: Revisions and reflections in 
response to comments received. J Clin Oncol. 2016;34(24):2925-34.

15. Zafar SY, Peppercorn JM, Schrag D, Taylor DH, Goetzinger AM, Zhong X, et al. The financial toxicity of cancer treatment: a pilot study assessing out-of-pocket expenses and the insured cancer patient's experience. Oncologist. 2013;18(4):381-90.

16. American CAncer Society Cancer Action Network. A National Poll: Facing Cancer in the Health Care System. 2010.

17. Zafar SY, McNeil RB, Thomas CM, Lathan CS, Ayanian JZ, Provenzale D. Population-based assessment of cancer survivors' financial burden and quality of life: a prospective cohort study. $J$ Oncol Pract. 2015;11(2):145-50.

18. Ramsey SD, Bansal A, Fedorenko CR, Blough DK, Overstreet KA, Shankaran V, Newcomb P. Financial insolvency as a risk factor for early mortality among patients with cancer. J Clin Oncol. 2016;34(9):980-6.

19. Hastert TA, Banegas MP, Hamel LM, Reed AR, Baird T, Beebe-Dimmer JL, et al. Race, financial hardship, and limiting care due to cost in a diverse cohort of cancer survivors. J Cancer Surviv. 2019;13(3):429-37.

20. Hastert TA, Kyko JM, Reed AR, Harper FWK, Beebe-Dimmer JL, Baird TE, et al. Financial hardship and quality of life among African American and white cancer survivors: The role of limiting care due to cost. Cancer Epidemiol Biomarkers Prev. 2019;28(7):1202-11.

21. Meropol NJ, Wong YN, Albrecht T, Manne S, Miller SM, Flamm AL, et al. Randomized trial of a webbased intervention to address barriers to clinical trials. J Clin Oncol. 2016;34(5):469-78.

22. Wong YN, Schluchter MD, Albrecht TL, Benson AB, Buzaglo J, Collins $M$, et al. Financial concerns about participation in clinical trials among patients with cancer. J Clin Oncol. 2016;34(5):479-87.

23. Wong YN, Egleston BL, Sachdeva K, Eghan N, Pirollo M, Stump TK, et al. Cancer patients' trade-offs among efficacy, toxicity, and out-of-pocket cost in the curative and noncurative setting. Med Care. 2013;51(9):838-45.

24. Markman M, Luce R. Impact of the cost of cancer treatment: an internet-based survey. J Oncol Pract. 2010;6(2):69-73.

25. Weckstein DJ, Thomas CA, Emery IF, Shea BF, Fleury A, White ME, et al. Assessment of perceived cost to the patient and other barriers to clinical trial participation. J Oncol Pract. 2011;7(5):330-3.

26. Dusetzina SB, Winn AN, Abel GA, Huskamp HA, Keating NL. Cost sharing and adherence to tyrosine kinase inhibitors for patients with chronic myeloid leukemia. J Clin Oncol. 2014;32(4):306-11.

27. Neugut AI, Subar M, Wilde ET, Stratton S, Brouse CH, Hillyer GC, et al. Association between prescription co-payment amount and compliance with adjuvant hormonal therapy in women with early-stage breast cancer. J Clin Oncol. 2011;29(18):2534-42.

28. Zullig LL, Peppercorn JM, Schrag D. Financial distress, use of cost-coping strategies, and adherence to prescription medication among patients with cancer. J Oncol Pract 2013, 9:60 s-63 s. 
29. Kent EE, Forsythe LP, Yabroff KR, Weaver KE, de Moor JS, Rodriguez JL, et al. Are survivors who report cancer-related financial problems more likely to forgo or delay medical care? Cancer. 2013;119(20):3710-7.

30. Ubel PA, Abernethy AP, Zafar SY. Full disclosure-out-of-pocket costs as side effects. N Engl J Med. 2013;369(16):1484-6.

31. Ubel PA: Doctor, first tell me what it costs. New York Times. 2013.

32. Blum D: How physicians can explain value to patients. ASCO Daily News. 2015.

33. Bath C. Disclosing medical costs can help avoid 'financial toxicity'. ASCO Post. 2013: 2.

34. Smith SK, Nicolla J, Zafar SY. Bridging the gap between financial distress and available resources for patients with cancer: a qualitative study. J Oncol Pract. 2014;10(5):e368-72.

35. Bullock AJ, Hofstatter EW, Yushak ML, Buss MK. Understanding patients' attitudes toward communication about the cost of cancer care. J Oncol Pract. 2012;8(4):e50-8.

36. Kelly RJ, Forde PM, Elnahal SM, Forastiere AA, Rosner GL, Smith TJ. Patients and physicians can discuss costs of cancer treatment in the clinic. J Oncol Pract. 2015;11(4):308-12.

37. Kim P. Cost of cancer care: the patient perspective. J Clin Oncol. 2007;25(2):228-32.

38. Hamel LM, Penner LA, Eggly S, Chapman R, Klamerus JF, Simon MS, et al. Do patients and oncologists discuss the cost of cancer treatment? An observational study of clinical interactions between African American patients and their oncologists. J Oncol Pract. 2017;13(3):e249-58.

39. Alexander GC, Casalino LP, Meltzer DO. Patient-physician communication about out-of-pocket costs. JAMA. 2003;290(7):953-8.

40. Board TA. Cancer patient financial navigation: Helping patients manage their costs while protecting program margins. Oncology Roundtable 2014.

41. Zolnierek KB, Dimatteo MR. Physician communication and patient adherence to treatment: a metaanalysis. Med Care. 2009;47(8):826-34.

42. Bandura A. Self-efficacy: toward a unifying theory of behavioral change. Psychol Rev. 1977;84(2):191-215.

43. Carrera PM, Kantarjian HM, Blinder VS. The financial burden and distress of patients with cancer: Understanding and stepping-up action on the financial toxicity of cancer treatment. CA Cancer J Clin. 2018;68(2):153-65.

44. Doyle C, Lennox L, Bell D. A systematic review of evidence on the links between patient experience and clinical safety and effectiveness. BMJ Open 2013,3(1).

45. Albrecht TL, Eggly SS, Gleason ME, Harper FW, Foster TS, Peterson AM, et al. Influence of clinical communication on patients' decision making on participation in clinical trials. J Clin Oncol. 2008;26(16):2666-73.

46. Cegala DJ, Chisolm DJ, Nwomeh BC. Further examination of the impact of patient participation on physicians' communication style. Patient Educ Couns. 2012;89(1):25-30. 
47. Eggly S, Hamel LM, Foster TS, Albrecht TL, Chapman R, Harper FWK, et al. Randomized trial of a question prompt list to increase patient active participation during interactions with black patients and their oncologists. Patient Educ Couns. 2017;100(5):818-26.

48. Street RL Jr, Tancredi DJ, Slee C, Kalauokalani DK, Dean DE, Franks P, et al. A pathway linking patient participation in cancer consultations to pain control. Psychooncology. 2014;23(10):1111-7.

49. Street RL Jr, Makoul G, Arora NK, Epstein RM. How does communication heal? Pathways linking clinician-patient communication to health outcomes. Patient Educ Couns. 2009;74(3):295-301.

50. de Haes $\mathrm{H}$, Bensing J. Endpoints in medical communication research, proposing a framework of functions and outcomes. Patient Educ Couns. 2009;74(3):287-94.

51. Cegala DJ, Street RL Jr, Clinch CR. The impact of patient participation on physicians' information provision during a primary care medical interview. Health Commun. 2007;21(2):177-85.

52. Street RL Jr, Slee C, Kalauokalani DK, Dean DE, Tancredi DJ, Kravitz RL. Improving physician-patient communication about cancer pain with a tailored education-coaching intervention. Patient Educ Couns. 2010;80(1):42-7.

53. Clayton JM, Butow PN, Tattersall MH, Devine RJ, Simpson JM, Aggarwal G, et al. Randomized controlled trial of a prompt list to help advanced cancer patients and their caregivers to ask questions about prognosis and end-of-life care. J Clin Oncol. 2007;25(6):715-23.

54. Brown RF, Bylund CL, Li Y, Edgerson S, Butow P. Testing the utility of a cancer clinical trial specific Question Prompt List (QPL-CT) during oncology consultations. Patient Educ Couns. 2012;88(2):3117.

55. Hibbard JH. Patient activation and the use of information to support informed health decisions. Patient Educ Couns. 2017;100(1):5-7.

56. Greene J, Hibbard JH. Why does patient activation matter? An examination of the relationships between patient activation and health-related outcomes. J Gen Intern Med. 2012;27(5):520-6.

57. Dimoska A, Butow PN, Dent E, Arnold B, Brown RF, Tattersall MH. An examination of the initial cancer consultation of medical and radiation oncologists using the Cancode interaction analysis system. $\mathrm{Br}$ J Cancer. 2008;98(9):1508-14.

58. Brandes K, Linn AJ, Butow PN, van Weert JC. The characteristics and effectiveness of Question Prompt List interventions in oncology: a systematic review of the literature. Psychooncology. 2015;24(3):245-52.

59. Dimoska A, Tattersall MH, Butow PN, Shepherd H, Kinnersley P. Can a "prompt list" empower cancer patients to ask relevant questions? Cancer 2008, 113(2):225-237.

60. Sansoni JE, Grootemaat P, Duncan C. Question Prompt Lists in health consultations: A review. Patient Educ Couns 2015.

61. Barton E, Moore TF, Hamel L, Penner L, Albrecht T, Eggly S. The influence of a question prompt list on patient-oncologist information exchange in an African-American population. Patient Educ Couns. 2020;103(3):505-13. 
62. Henselmans I, de Haes HC, Smets EM. Enhancing patient participation in oncology consultations: a best evidence synthesis of patient-targeted interventions. Psychooncology. 2013;22(5):961-77.

63. Eggly S, Hamel LM, Heath E, Manning MA, Albrecht TL, Barton E, et al. Partnering around cancer clinical trials (PACCT): study protocol for a randomized trial of a patient and physician communication intervention to increase minority accrual to prostate cancer clinical trials. BMC Cancer. 2017;17(1):807.

64. O'Neill SC, Vadaparampil ST, Street RL Jr, Moore TF, Isaacs C, Han HS, et al. Characterizing patientoncologist communication in genomic tumor testing: The 21-gene recurrence score as an exemplar. Patient Educ Couns 2020.

65. Jayasekera J, Vadaparampil ST, Eggly S, Street RL Jr, Foster Moore T, Isaacs C, et al. Question prompt list to support patient-provider communication in the use of the 21-Gene Recurrence Test: Feasibility, acceptability, and outcomes. JCO Oncol Pract. 2020;16(10):e1085-97.

66. Hamel LM, Thompson HS, Albrecht TL, Harper FW. Designing and testing apps to support patients with cancer: Looking to behavioral science to lead the way. JMIR Cancer. 2019;5(1):e12317.

67. Alexander GC, Casalino LP, Tseng CW, McFadden D, Meltzer DO. Barriers to patient-physician communication about out-of-pocket costs. J Gen Intern Med. 2004;19(8):856-60.

68. Altomare I, Irwin B, Zafar SY, Houck K, Maloney B, Greenup R, et al. Physician experience and attitudes toward addressing the cost of cancer care. J Oncol Pract. 2016;12(3):247-8.

69. Eldridge SM, Chan CL, Campbell MJ, Bond CM, Hopewell S, Thabane L, et al. CONSORT 2010 statement: extension to randomised pilot and feasibility trials. Pilot Feasibility Stud. 2016;2:64.

70. Peterson AM, Harper FW, Albrecht TL, Taub JW, Orom H, Phipps S, et al. Parent caregiver self-efficacy and child reactions to pediatric cancer treatment procedures. J Pediatr Oncol Nurs. 2014;31(1):1827.

71. Maly RC, Frank JC, Marshall GN, DiMatteo MR, Reuben DB. Perceived efficacy in patient-physician interactions (PEPPI): validation of an instrument in older persons. J Am Geriatr Soc. 1998;46(7):88994.

72. Gilligan T, Bohlke K, Baile WF. Patient-Clinician Communication: American Society of Clinical Oncology Consensus Guideline Summary. J Oncol Pract. 2018;14(1):42-6.

73. Jagsi R, Ward KC, Abrahamse PH, Wallner LP, Kurian AW, Hamilton AS, et al. Unmet need for clinician engagement regarding financial toxicity after diagnosis of breast cancer. Cancer. 2018;124(18):3668-76.

74. Jayadevappa R, Schwartz JS, Chhatre S, Gallo JJ, Wein AJ, Malkowicz SB. The burden of out-ofpocket and indirect costs of prostate cancer. Prostate. 2010;70(11):1255-64.

75. Guy GP Jr, Ekwueme DU, Yabroff KR, Dowling EC, Li C, Rodriguez JL, et al. Economic burden of cancer survivorship among adults in the United States. J Clin Oncol. 2013;31(30):3749-57.

76. Bradley CJ, Yabroff KR, Dahman B, Feuer EJ, Mariotto A, Brown ML. Productivity costs of cancer mortality in the United States: 2000-2020. J Natl Cancer Inst. 2008;100(24):1763-70. 
77. Trogdon JG, Liu X, Reeder-Hayes KE, Rotter J, Ekwueme DU, Wheeler SB. Productivity costs associated with metastatic breast cancer in younger, midlife, and older women. Cancer 2020.

78. Trogdon JG, Baggett CD, Gogate A, Reeder-Hayes KE, Rotter J, Zhou X, et al. Medical costs associated with metastatic breast cancer in younger, midlife, and older women. Breast Cancer Res Treat. 2020;181(3):653-65.

\section{Figures}

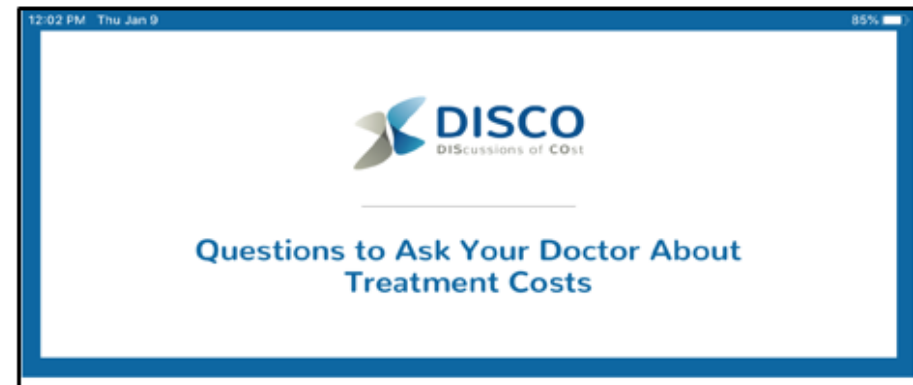

There is a lot to consider when it comes to treating cancer. One thing many patients don't think about is the cost of treatment and other expenses.

- On the next few screens, we will ask you to answer some questions about yourself.

- Nobody but you will see your answers, and this will in no way affect your treatment.

- Your answers will help us choose some questions that you could ask your doctor or other provider about treatment costs.

- You will see these questions at the end of the survey.

- You can choose to ask these questions or not.

\section{Start Survey}

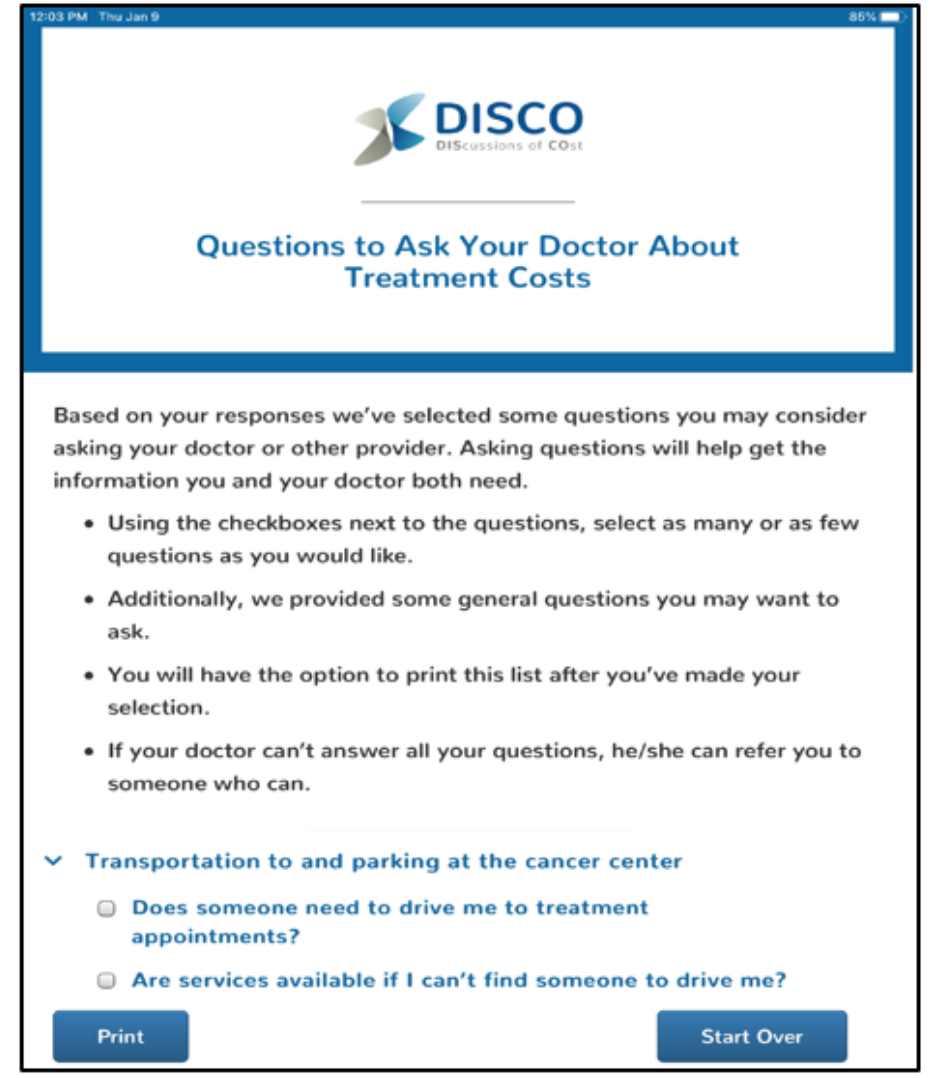

Based on your responses we've selected some questions you may conside asking your doctor or other provider. Asking questions will help get the tion you and your doctor both need. questions as you would like.

Additionally, we provided some general questions you may want to

You will have the option to print this list after you've made your If your doctor can't answer all your questions, he/she can refer you to someone who can.

Does someone need to drive me to treatment appointments?

\section{Figure 1}

DISCO App QPL Introduction Screens

\section{Supplementary Files}

This is a list of supplementary files associated with this preprint. Click to download.

- DISCOCONSORTChecklist.doc 